\title{
Figuring Configuration: "everyday" users and end-user configuration of Pervasive Computing Environments
}

\author{
Thom Heslop \\ Dept. of Informatics \\ University of Sussex \\ Falmer, Sussex. \\ T.T.Heslop@sussex.ac.uk
}

\begin{abstract}
The research outlined investigates strategies that nonprogramming or "everyday" users may take in interaction with a Pervasive Computing Environment within relevant domains specified by them using a novel probe methodology developed with reference to theories of appropriation of technology and Vygotsky's "Tool and Result" methodology. A hypothesis of configuration policy styles is tested and types of everyday user styles and likely task domains are identified and discussed.
\end{abstract}

\section{Categories and Subject Descriptors}

H.1.2 [Models and Principles]: User / Machine Systems human factors.

\section{General Terms}

Design, Experimentation, Human Factors.

\section{Keywords}

Pervasive, Ubiquitous, User-centered design, configuration, methodology, interaction design, Natural Language.

\section{RESEARCH PROBLEM}

With the advent of computer technologies embedded in a variety of devices and the convergence of wireless technologies with the Internet has come the possibility of a ubiquitous or pervasive computing environment involving many interacting complex systems. There is a growing recognition among researchers that people are likely to feel the need to control these environments - studies show that people can feel at the mercy of ubiquitous systems (Edwards [6], Barkhuus [1]) rather than in control of them. If this is the case then it would mean that the configuration of Pervasive Computing Environments (PCEs) is most likely to be in control of non-computing / programming, or "everyday" individuals and groups, especially within the domestic and public sphere. This poses a number of challenges for HCI research:

- Greenfield [7] points out that interacting with PCEs will involve new modes that are radically different to what most domestic users used to. What strategies are they likely to adopt when configuring these environments?

- As noted above, people can feel uncomfortable with ubiquitous systems. Researchers such as Rogers [11] also point out that these systems may not be suitable for all situations. It is therefore important to identify which areas of their lives and routines everyday users can envision an application for PCEs. Which domains will be relevant to

Published by the British Computer Society

Volume 2 Proceedings of the 21 st BCS HCI Group Conference HCI 2007, 3-7 September 2007, Lancaster University, UK

Devina Ramduny-Ellis \& Dorothy Rachovides (Editors) them?

- There is a growing body of research into interfaces for enduser configuration (examples can be found in [4] [8] [10] and [13]. On the main, these are primarily policy based (where the user specifies conditional rules for the operation of the system) and tend to conceive of policy composition as either the connection of devices to enact the users wishes or one of definition of goals and tasks with reference to the functionality of the system. However, ethnographic work [3] has shown that people do not conceive of their goals in terms of device behavior but rather their needs. Furthermore goal and tasks within the domestic area are often unclear. It can be argued that the interfaces mentioned above are therefore too low-level for most everyday users to operate successfully. What is the level that they will feel comfortable with?

- Finally, with the present state of incomplete or as yet undefined systems, what methodology can we use to evaluate these important issues?

\section{CONTRIBUTION TO HCI RESEARCH}

Identification and classification of configuration styles (in the form of policies) most likely to be used by non-programming users and task domains the use of the systems would be most appropriate for, contribution to understanding of the sort of language likely to be used by non programming users, (important as one of the main modes of interaction with PCEs is likely to be via Natural Language Interfaces). A novel probe methodology for discovering the suitability of a proposed computational model for real users.

\section{PROPOSED SOLUTIONS}

Pilot studies carried out as part of a research project into the configuration of a PCE using policies defined in Natural Language [14] at the University Of Sussex produced the hypothesis that the range of NL utterances would fall into the following styles: Trigger policies where activity is initiated when a particular event occurs, (otherwise known as eventcondition-action rules), Refinement policies where defaults are set or overwritten and Deontic policies which specify circumstances when a service is allowed or place constraints on possible values in a request. It was further predicted that the knowledge of devices and services available would influence style and constrain the content of these policies. However, these studies were limited to a discrete domain (office printing), where goals would likely be clear to the user. Part of this research proposes to test this hypothesis over the broader and far less well defined domestic domain where these PCEs are likely to be in operation.

In order to gather examples of policies garnered from "everyday" users studies were needed. The design of these user studies presented the following challenges

- Most existing methodologies for User studies are based in the discipline of User Centred Design, which concentrates 
on the goals and tasks of the user. The system on which the required user studies are centred may be unfamiliar to the interviewee, who is unlikely to have any clearly defined goal or tasks within its domain.

- There is as yet no fully operational PCE running on the computational model under investigation. This would rule out an observational or ethnographic approach.

In order to overcome these problems a multi-stage Vygotskyan "tool and result" methodology [9] was designed, where the results of the previous stage of the study are used as tools or support in the next stage. It is my hypothesis that the methodology described in the next section will produce two results: a) it will identify likely use domains allowing us to anticipate where technology likely to be suitable and b) help users to conceive of and express goals and tasks that technology can be used for, allowing us to identify types of policies.

\section{METHODOLOGY}

Proponents of theories of the appropriation of technologies (such as Dourish [5] and Carroll [2]) argue that in order to make use of a new technology, users must make it "meaningful" to themselves by placing it within their own practices. As shown in the studies by Davidoff [3] and Tolmie [12]. people think of their domestic lives in terms of routines rather than discrete goal or tasks. In order to get useful policies from the interview subjects it was decided to leverage their conception of their daily routines and, in particular, how they would envision how these could be supported by a PCE in the form of a 'Virtual Noticeboard' system. This would show useful information from a variety of different sources and would have screens located in a number of locations around a domestic setting as well as mobile devices and sites outside the home (car, office). Over the series of studies, 20 people were interviewed. They were all professional people between the ages $35-50$, with normal everyday technical experience (i.e. non-programming) and who are used to running households containing a number of people. It is envisioned that this demographic will form the likely users for this sort of PCE.

There were three stages to the series of studies:

- The first stage of interviews concentrated on discovering likely routine domains - what domestic routines the technology would be most likely used to support. The interviewees were introduced to the 'Virtual Noticeboard' system using a mock-up of a likely onscreen layout showing the output from different information sources. The interviewer then explained the concept of a PCE and services, the underlying model of configuration via policy definition and the conditional nature of policies, with examples. The interviewee was asked to consider where this technology may be of use in supporting their daily life routines and, if possible, to formulate some policies of their own.

- In the second study the interviewees were re-introduced (if they had taken part in the first stage) or introduced (as in the first stage) to the system and the concept of policies. The routine domains identified from the first stage were outlined, and the interviewees were supplied with lists of possible services that would carry out policies relevant to each domain.

- For the third stage of interviews the methodology was as before, using the same scenario and materials with the addition of focused goals in the guise of small scenarios (derived from analysis of interviews for Stage Two) encapsulated by a high level "goal-oriented" phrase, such as "Maintain my heating". The interviewees were then asked to try to break these down into more specific policies over a number of task domains again derived from ones commonly occurring in the Stage Two interviews.

\section{CURRENT STATUS}

I am currently formalising the methodology described above preparing the final studies as described in the "Future Work" section.

\section{INTERIM CONCLUSIONS}

\subsection{Identified Task Domains}

No usable policies were forthcoming in first stage from any of the interviewees, indicating that more support for policy formulation than just the idea of the technology was needed (in keeping with the idea of Appropriation). However, three commonly re-occurring high-level areas were identified at this stage: Child, Food / Meal and Home Maintenance. These were used as the basis for the second stage of interviews.

The second stage gave a finer grained picture of task areas that cropped up regularily: Media Control, Child / People care, Food \& Meals Maintenance, Calendar co-ordination and Heating \& Energy Control. These were used as the basis of the focused goals used in the third stage, where the majority of the policy corpus was formed.

\subsection{Policies Styles}

A corpus of 184 policies was collected and analysed to test the validity of the style hypothesis.

$80 \%$ of the policy corpus conforms to the predicted types of policy: 38\% Trigger and 21\% each Refinement and Deontic However it was noted that there are sub-types of Trigger policies - as well as the expected event-based ones, there were also a number of time-based policies (example: "From 1st July 2005 to 6th July 2005 collect all key stage three articles on "the chartists" and file in Chloe's school folder" and state-based polices (example: "Using the set of stock cupboard articles, keep me informed if I'm running out".)

$20 \%$ lay outside of the original classification schema. Other styles identified are:

Time-dependent default overwrites (example: "At 6PM the temperature in Bedroom 3 should be $x$ and at 7.30PM it should be changed to $x$-3 degrees".)

Requests: this involves asking the system to provide information or offer a solution based on a given criteria, such as "Suggest favourite recipes depending on the weather forecast for tomorrow at 8pm". This style is mostly found in the policies formed in the Food Maintenance area.

Aggregation or "Pipe" policies: essentially a combination of styles - specific actions that become an event that triggers other actions which in turn will trigger actions, set defaults or specify circumstances (example: "Check diary for destinations in the next 24hours, search for best route and transfer information to navigation system.")

Rather than the being constrained and influenced by knowledge of the devices and services, the style and language of the collected policies often have no discernable reference to either, supporting the contention that users tend to think of their goals in terms of their needs.

Finally, the task domains made no real difference to types of policies formed but some users showed a particular bias to Deontic and Refinement policies while others were more likely 
to define Trigger policies bringing up the issue of "personal style" in defining policies.

\section{FUTURE WORK}

A tentative plan for further work would include:

a) proper formalisation of methodology, b) further investigation of the prevalence of task type within domains to build up a richer picture of application of PCEs, c) policy style - see if we can get users to specify policies with explicit references to services / devices: use this to test both the level at which "everyday" users are comfortable using the technology and the formalized methodology.

\section{REFERENCES}

[1] Barkhuus, L., Dey, A.,: Is Context-Aware Computing Taking Control away From The User? Three Levels Of Interactivity Examined

[2] Carroll, J., (2004), Completing Design In Use: Closing The Appropriation Cycle, White Paper, (University Of Melbourne),

www.dis.unimelb.edu.au/oasis/AppropnWPaper.pdf

[3] Davidoff, S., Lee, M.K., Yiu, C., Zimmerman, J., Dey, A.K, Principles Of Smart Home Control. Dourish, P., Friday, A., eds, Ubicomp 2006 Berlin Heidelberg: Springer Verlag pgs 19-34 2006,

[4] Dey, A., Hamid, R., Beckmann, C., Li, I., Hsu, D., $a$ CAPpella: Programming by Demonstration of ContextAware Applications. In CHI 2004, April 24-29, 2004, Vienna, Austria pgs 34-40

[5] Dourish, P. Where the Action Is: The Foundations of Embodied Interaction. MIT Press, Cambridge: 2001. [6] Edwards, K., Grinter, R., (2001) At Home With Ubiquitous Computing : Seven Challenges. In UbiComp 2001

[7] Greenfield, A. (2006), Everyware: The Dawning Age Of Ubiquitous Computing, Berkeley: New Riders Press

[8] Humble, J., Crabtree, A, Hemmings, T., Akesson, K-P., Koleva, B., Rodden, T., Hansson, P., "Playing with the Bits" User-configuration of Ubiquitous Domestic Environments, http://ubicomp.org/ubicomp2004 2003
[9] Newman, F and Holzman, L., Lev Vygotsky: Revolutionary Scientist, Routledge Press, London 1993.

[10] Newman, M., Sedivy, J., Neuwirth, C.M., Edwards, W.K., Hong, J.L., Izadi, S., Marcelo, K., Smith, T.F., Designing For Serendipity,

www2.parc.com/cs1/projects/speakeasy/papers/dis02.pdf

[11] Rogers, Y., Moving On From Weiser's Vision of Calm Computing: Engaging Ubicomp Experiences, in Dourish, P., Friday, A., eds, Ubicomp 2006 Berlin Heidelberg: Springer Verlag pgs 404-421 2006

[12] Tolmie, P., Pycock, J., Diggins, T., MacLean, A., Karsentty, A. (2002) Unremarkable Computing, Conference On Human Factors in Computing Systems , SIGCHI Minneapolis pgs 399-406, 2002.

[13] Truong, K, Huang, E., \& Abowd, G., (2004), CAMP: A Magnetic Poetry interface for End-User Programming of Capture Applications for the Home. Proceedings of the Sixth International Conference on Ubiquitous Computing (Ubicomp 2004; Nottingham, UK)

[14] Weeds, J., Keller, W., Weir, D., Wakeman, I., Rimmer, J., Owen, T, Natural Language Expression of User Policies in Pervasive Computing Environments, OntoLex, Lisbon, Portugal, May 2004. 